\title{
Research on Financial Risk Evaluation of Railway Logistics Based on BP Neural Network Model
}

\author{
Mengna Li, Xiangfei Yang, Congcong Xin, Jie Zhang \\ Lanzhou Jiaotong University, Lanzhou, China
}

Keywords: Modern logistics; logistics finance; risk assessment BP neural network; risk grade.

\begin{abstract}
This paper analyzes the risk factors of developing logistics finance business in railway enterprises, identifies the risks from two aspects of external risk and internal risk, and constructs the evaluation index system of railway logistics financial risk. Based on the analysis of BP neural network structure, the training and testing of the sampling samples are carried out by using the neural network, and the risk grade of each influencing factor is obtained, which provides a basis for judging the risk prevention and control of railway logistics finance.
\end{abstract}

\section{Introduction}

The operation mode of railway logistics finance is not mature enough, it is difficult to avoid many risks brought about by logistics finance, thus bringing certain economic losses to railway logistics enterprises. In order to avoid large economic losses to railway logistics enterprises, it is very important to make an accurate evaluation according to the risks that railway logistics enterprises need to deal with, and to establish a reliable evaluation model of railway logistics financial risks. Therefore, from the point of view of railway logistics enterprises, through the use of BP neural network model, a set of relatively complete railway logistics financial risk evaluation system will be constructed. In order to deal with railway logistics financial risk to make an accurate evaluation and countermeasures.

\section{Establishment of Railway Logistics Financial Risk Identification and Evaluation System}

\subsection{Financial Risk Identification and Risk Factors Analysis of Railway Logistics}

There are two business models: inventory financing and trade financing. The operation process of these two business models is similar to that of inventory. The two business processes can identify the financial risks of railway logistics from two aspects, namely, internal risk and external risk.

\subsubsection{External Risk}

The external risk refers to the risks caused by the external environment such as cooperative enterprise, market, law and environment, mainly including:

Cooperative venture risk.Generally from the financial situation of the partner. Credit status and operating status of the risk identification in three aspects.

Market risk. Including the risk of domestic and foreign economic situation and the risk of realisation of pledge.

Legal risk. Legal risk refers to the risk caused by the soundness of domestic laws and regulations.

Environmental risk. Environmental risks including policy risk and natural risk .

\subsubsection{Internal Risk}

The internal risk of railway logistics finance refers to the risk caused by the way of supervision and self - factors inside the railway enterprise, mainly including:

Quality Risk.Reduce the market value of the pledge and bring the risk to the railway logistics enterprise. Risk factors: quality risk of pledge.

Operational and regulatory risks. Mainly including organization structure risk, supervision operation risk, supervision information system risk.

Contract risk. Contract risk is the commonness of logistics finance business. 
Risk of warehouse receipt. Truthfulness risk of warehouse receipt, normative risk of filling out warehouse receipt and risk of completeness of warehouse receipt operation procedure.

\subsection{Establishment of Evaluation Index System of Railway Logistics Financial Risk}

By identifying the risk factors of railway logistics finance, the index system of railway logistics financial risk is constructed as shown in Table 1.

Table 1 Railway logistics financial risk evaluation index system

\begin{tabular}{|c|c|c|}
\hline class indexes & secondary indexes & risk factor \\
\hline \multirow{8}{*}{ external Risk $L_{1}$} & \multirow{3}{*}{ cooperative venture risk $R_{1}$} & Financial risk $W_{1}$ \\
\hline & & credit risk $W_{2}$ \\
\hline & & Manage risk $W_{3}$ \\
\hline & \multirow{2}{*}{ market risk $R_{2}$} & Domestic and foreign economic situation risk $W_{4}$ \\
\hline & & Pledge realization risk $W_{5}$ \\
\hline & legal risk $R_{3}$ & Sound laws and regulations risk $W_{6}$ \\
\hline & \multirow{2}{*}{ environmental risk $R_{4}$} & policy risk $W_{7}$ \\
\hline & & natural risk $W_{8}$ \\
\hline \multirow{8}{*}{ internal risk $L_{2}$} & quality risk $R_{5}$ & pledge quality risk $W_{9}$ \\
\hline & \multirow{3}{*}{ operational and regulatory risks $R_{6}$} & organizational structure risk $W_{10}$ \\
\hline & & regulatory operational risk $W_{11}$ \\
\hline & & regulatory information system risk $W_{12}$ \\
\hline & contract Risk $R_{7}$ & contract risk $W_{13}$ \\
\hline & \multirow{3}{*}{ warehouse receipt risk $R_{8}$} & warehouse receipt authenticity risk $W_{14}$ \\
\hline & & normative risk of warehouse receipt filling $W_{15}$ \\
\hline & & risk of completeness of warehouse receipt operating procedures $W_{16}$ \\
\hline
\end{tabular}

\section{Bp Neural Network}

\subsection{Bp Neural Network Theory}

BP neural network is a one-way propagation multi-layer feedforward neural network proposed by Rumelhart in 1986.There are usually three or more neurons, including the input layer, the hidden layer and the output layer, the neurons between adjacent layers realize full connection, and there is no connection between the neurons of each layer. The structure of BP neural network is shown in figure 1.

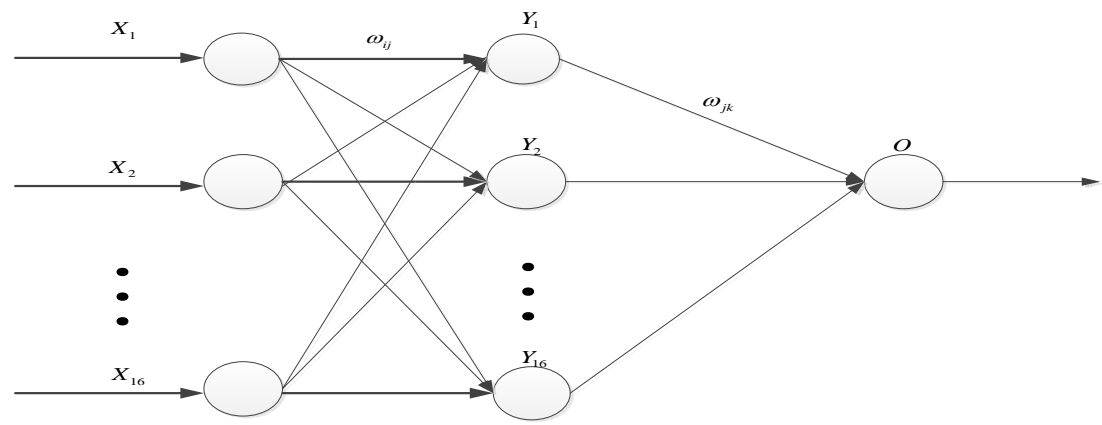

Figure 1. BP neural network structure

\subsection{Learning Algorithm of Bp Neural Network}

In this paper, a three-layer neural network is used, 16 risk assessment factors are taken as the number of neurons in the input layer of the model, and 1 comprehensive value of the risk output layer of the model.Empirical formula for determining the number of neurons in the hidden layer:

$$
h=\sqrt{n+a}+b
$$

In the formula: $h$ is the number of neurons in the hidden layer; $n$ is the number of neurons in the input layer; $a$ is the number of neurons in the output layer; $b$ is the regulating constant, and the range is [0-10].According to the formula, the range of values of the hidden layer is obtained [5-15], the specific number is determined according to the training condition of the model. We selecting 10 as the number of hidden layer neurons.

Positive propagation phase of input information :

Input layer: 
Hidden layer:

$$
\mathrm{Xn}=(\mathrm{X} 1, \mathrm{X} 2, \cdots, \mathrm{Xi}, \cdots, \mathrm{X} 16)^{T}
$$

$$
\mathrm{yi}=f\left(\text { net }_{j}\right)=f\left(\sum_{i=1}^{16} v_{i j} x_{i}-\theta_{j}\right)
$$

Output layer:

$$
\mathrm{o}=f(\text { net })=f\left(\sum_{i=1}^{15} \omega_{j} y_{i}-\theta\right)
$$

3.2.1 In the Formula: $\mathrm{V}$ and $\omega$ are the Connection Between Weights and Neurons; $\theta$ is the Threshold of the Neuron.

The function $y=f(x)$ is the conversion function of the neuron is :

$$
\mathrm{y}=\frac{1}{1+e^{-x}}
$$

The back Propagation stage of error Information.The definition error function is represented as:

$$
E=\sqrt{\sum_{t=1}^{t}(d-o)^{2}}
$$

In the formula: $d$ and o are the expected output and the actual output of the neural network respectively; $t$ is the number of training samples of the neural network.

The error of the output layer is:

$$
\delta^{0}=-\frac{\partial E}{\partial n e t}=(d-o) o(1-o)
$$

The error of the hidden layer is:

$$
\delta_{j}^{y}=-\frac{\partial E}{\partial n e t_{j}}=\left(\delta^{o} \omega_{j}\right) y_{j}\left(1-y_{j}\right)
$$

The connection weights are revised as follows:

$$
\Delta \omega_{j}=\eta \delta^{o} y_{j} ; \Delta v_{i j}=\eta \delta_{j}^{y} x_{i}
$$

The threshold correction is:

$$
\Delta \theta=\eta \delta^{o} ; \Delta \theta_{j}=\eta \delta_{j}^{y}
$$

In the formula: ${ }$ is learning efficiency.The general values are between [0.01-0.08], here we take 0.05 .

\section{Establishment of Railway Logistics Financial Risk Evaluation Model Based on Bp Neural Network}

\subsection{Data Collection and Processing}

10 sample railways was carried out according to 10 experts. Data compiled into risk assessment indicators are shown in Table 2, sample set for training and testing BP Neural Network.The 16 standard risk values $\mathrm{Wj}$ of each sample in Table 2 correspond to 16 risk factors in the financial risk index system of railway logistics, which is used as the input value of neural network, The comprehensive evaluation value $\mathrm{T}$ of logistics financial risk is the expected output value of neural network. 
Table 2 Risk evaluation index data

\begin{tabular}{|c|c|c|c|c|c|c|c|c|c|c|c|}
\hline \multicolumn{2}{|c|}{$\begin{array}{c}\text { Sample serial } \\
\text { number }\end{array}$} & 1 & 2 & 3 & 4 & 5 & 6 & 7 & 8 & 9 & 10 \\
\hline \multirow{16}{*}{ input } & $W_{1}$ & 0.0286 & 0.0429 & 0.0357 & 0.0357 & 0.0500 & 0.0357 & 0.0143 & 0.0357 & 0.0357 & 0.0286 \\
\hline & $W_{2}$ & 0.0381 & 0.0381 & 0.0286 & 0.0286 & 0.0190 & 0.0476 & 0.0190 & 0.0381 & 0.0381 & 0.0381 \\
\hline & $W_{3}$ & 0.0214 & 0.0143 & 0.0214 & 0.0071 & 0.0214 & 0.0143 & 0.0214 & 0.0429 & 0.0071 & 0.0143 \\
\hline & $W_{4}$ & 0.0226 & 0.0375 & 0.0272 & 0.0285 & 0.0376 & 0.0320 & 0.0420 & 0.0331 & 0.0265 & 0.0281 \\
\hline & $W_{5}$ & 0.0381 & 0.0381 & 0.0286 & 0.0286 & 0.0190 & 0.0381 & 0.0286 & 0.0381 & 0.0286 & 0.0286 \\
\hline & $W_{6}$ & 0.0143 & 0.0190 & 0.0238 & 0.0143 & 0.0286 & 0.0143 & 0.0238 & 0.0143 & 0.0190 & 0.0143 \\
\hline & $W_{7}$ & 0.0226 & 0.0375 & 0.0272 & 0.0285 & 0.0376 & 0.0320 & 0.0420 & 0.0331 & 0.0265 & 0.0207 \\
\hline & $W_{8}$ & 0.0195 & 0.0637 & 0.0663 & 0.0629 & 0.0671 & 0.0634 & 0.0603 & 0.0638 & 0.0602 & 0.0255 \\
\hline & $W_{9}$ & 0.0595 & 0.0476 & 0.0476 & 0.0238 & 0.0357 & 0.0357 & 0.0143 & 0.0357 & 0.0357 & 0.0286 \\
\hline & $W_{10}$ & 0.0223 & 0.0277 & 0.0175 & 0.0193 & 0.0479 & 0.0456 & 0.0503 & 0.0561 & 0.0237 & 0.0487 \\
\hline & $W_{11}$ & 0.0201 & 0.0559 & 0.0612 & 0.0537 & 0.0576 & 0.0537 & 0.0579 & 0.0638 & 0.0453 & 0.0245 \\
\hline & $W_{12}$ & 0.0201 & 0.0382 & 0.0273 & 0.0270 & 0.0572 & 0.0473 & 0.0427 & 0.0531 & 0.0370 & 0.0371 \\
\hline & $W_{13}$ & 0.0619 & 0.0598 & 0.0637 & 0.0621 & 0.0538 & 0.0605 & 0.0537 & 0.0145 & 0.0256 & 0.0602 \\
\hline & $W_{14}$ & 0.0649 & 0.0611 & 0.0637 & 0.0629 & 0.0637 & 0.0578 & 0.0512 & 0.0216 & 0.0225 & 0.0630 \\
\hline & $W_{15}$ & 0.0302 & 0.0210 & 0.0140 & 0.0335 & 0.0143 & 0.0183 & 0.0165 & 0.0233 & 0.0174 & 0.0269 \\
\hline & $W_{16}$ & 0.0234 & 0.0311 & 0.0283 & 0.0275 & 0.0163 & 0.0205 & 0.0315 & 0.0265 & 0.0165 & 0.0221 \\
\hline \multicolumn{2}{|c|}{ Desired output $\mathrm{T}$} & 0.5076 & 0.6335 & 0.5821 & 0.5440 & 0.6268 & 0.6168 & 0.5695 & 0.5937 & 0.4654 & 0.5093 \\
\hline
\end{tabular}

\subsection{Data Collection and Processing}

The risk evaluation results of railway logistics finance are divided into five grades, which are I, II, III, IV and V, corresponding evaluation interval [0.0-0.2], [0.2-0.4], [0.4-0.6], [0.6-0.8], [0.8-1.0]. The comparison table between the output value and expected output value of BP neural network is shown in Table 3.

Table 3 Comparison of output value and expected output value of bp neural network

\begin{tabular}{|c|c|c|c|c|c|c|c|c|}
\hline Sample serial number & 1 & 2 & 3 & 4 & 5 & 6 & 7 & 8 \\
\hline desired output & 0.5076 & 0.6335 & 0.5821 & 0.5440 & 0.6268 & 0.6168 & 0.5695 & 0.5937 \\
\hline actual output & 0.5075 & 0.6317 & 0.5829 & 0.5423 & 0.6262 & 0.6172 & 0.5688 & 0.5936 \\
\hline error value & 0.0001 & 0.0018 & -0.0008 & 0.0017 & 0.0006 & -0.0004 & 0.0007 & 0.0001 \\
\hline Evaluation results & III & IV & III & III & IV & IV & III & III \\
\hline
\end{tabular}

As shown in Table 3, the actual output of the 8 sets of training samples is very close to the expected output, and the results of the evaluation are the same. It can be used for the generalization training of the 2 groups of samples. The results obtained from pan-China are shown in Table 4.

Table 4 Comparison of expected and actual output in the test stage

\begin{tabular}{|c|c|c|}
\hline Sample serial number & 9 & 10 \\
\hline desired output & 0.4654 & 0.5093 \\
\hline actual output & 0.4654 & 0.5092 \\
\hline error value & 0 & 0.0001 \\
\hline evaluation results & III & III \\
\hline
\end{tabular}

Table IV shows that the error value of the test sample is small, and the model has certain generalization ability, which can be used to accurately evaluate the risk of railway logistics finance.

\section{Conclusion}

Improper prevention and control of risks will bring huge losses to railway enterprises. There are many uncontrollable factors involved, this paper systematically analyzes the various factors that railway enterprises will face, and establishes a logistics financial risk evaluation system suitable for railway enterprises. Because railway enterprises have just started logistics financial business. There are not many risk data available for collection, and the construction of risk index system needs to be further improved, but it is worth making clear that the risk evaluation of railway logistics finance is based on BP neural network model.It is of reference and significance for the prevention and control of logistics financial risk of railway. 


\section{Acknowledgements}

This research work was financed by Research and Development Project of Science and Technology of China Railway (contract number: 2017X010-G).

\section{References}

[1]. GERTZOF M. The changing face of asset. Based lending [J]. Commercial Lending Review, 2000, 15(4): 1-18.

[2]. FENMORE E. Making purchase-order fmancing work for you [J]. The Secured Lender, 2004, 60(2): $20-24$.

[3]. BARSKY N P, CATANACHA H. Evaluating business risks in the commercial lending decision [J]. Commercial Lending Review, 2005(3): 3-10. 